\title{
MECHANISMS OF RESPIRATORY FAILURE UNDER BARBITURATE ANESTHESIA (EVIPAL, PENTOTHAL) ${ }^{1}$
}

\author{
By HENRY K. BEECHER AND CARL A. MOYER 2 \\ (From the Anesthesia Laboratory of the Harvard Medical School at the Massachusetts \\ General Hospital, Boston)
}

(Received for publication May 19, 1941)

With the growing use of the barbiturates in anesthesia and in medicine in general, it becomes increasingly important to understand the hazards this entails, not only so that accidents of the past may be explained but, chiefly, so that they can be prevented in the future. In this study our attention has been directed to the respiration. While other systems may also be affected adversely by the barbiturates, the respiration frequently gives the first warning of impending difficulties. Respiratory failure often plays an important part in death under these agents. This study was designed primarily to investigate the mechanisms leading to respiratory failure under evipal and pentothal anesthesia. Since the barbiturates are qualitatively very similar in their actions, it is probable that the mechanisms described here apply to many members of the group.

\section{EQUIPMENT AND PROCEDURES}

Animals. Mongrel dogs weighing about 10 kilograms were employed. Blood pressure was recorded by means of a Ludwig manometer from the femoral artery. The representative material presented here was chosen from that obtained in experiments on 43 dogs under the two anesthetic agents considered.

Anesthesia. Evipal sodium [ 1 methyl $5 \Delta^{\prime}$ cyclohexenyl 5 methyl barbiturate] in 10 per cent aqueous solution was administered intravenously in an initial dose of $50 \mathrm{mgm}$. per kgm. body weight. This was supplemented intravenously as needed during the preparation of the animal and the course of the experiment. Pentothal sodium [ethyl (1-methyl-butyl) thiobarbiturate] in 5 per cent aqueous solution was administered intravenously in an initial dose of $25 \mathrm{mgm}$. per $\mathrm{kgm}$. body weight. Additional anesthetic was added intravenously as needed. The points illustrated hold true for both agents. Sometimes one agent, sometimes the other, is used to demonstrate a given point.

Depth of anesthesia was controlled as carefully as possible by observation of the state of a spinal reflex. The flexion reflex of the left semitendinous muscle was

\footnotetext{
1 Supported in part by a grant-in-aid from the Executive Committee of E. R. Squibb and Sons.

2 Fellow of the National Research Council.
}

evoked by electrical stimulation of the central end of the cut left sciatic nerve. The electrodes were chlorided silver wires flattened and perforated and stitched to the nerve. Insulation was insured with cotton packing around the electrodes and nerve. These electrodes were connected with the secondary coil of a Harvard inductorium. The primary was activated with a 1.5 volt dry cell. A hand-operated mercury contact key and a signal magnet were placed in circuit with this. The strength of the stimulating current was adjusted to give approximately a maximal response. The ipsilateral nerves to the hamstring muscles were left intact so that contractions of the divided semitendinous muscle might be recorded on the smoked drum. Essentially isometric recording was obtained by employing a tempered steel recording lever. The information as to depth of anesthesia obtained from the spinal reflex records was supplemented by frequent notes as to the state of the corneal and lid reflexes. Sluggish reflexes were designated as one plus and very active ones as two plus.

Respiratory apparatus and recording. Three simultaneous records were made of the respiration: The tidal excursions were recorded by means of a Hutchinson spirometer, specially constructed so as to allow an artificial increase or decrease in intrapulmonary pressure to be made during the recording (4); the intercostal and diaphragmatic respirations were recorded, as described by Gesell and Moyer (3), by means of paper bands which encircled the midthorax and the midabdomen of the torso from which the hair had been clipped; the segmental and combined respiratory responses were recorded on a smoked drum where an upstroke corresponds to inspiration. The animal was connected to an airway (where airflow was directed by two Tissot valves) and from this to the Hutchinson spirometer and a 60 liter steel tank, usually two-thirds filled with water. Interconnections through brass steam pressure valves permitted instantaneous shift to the gas mixtures contained in any one of three such steel tanks without interruption during recording. A soda lime cannister was inserted into the expiratory half-circuit of the system in such a way that the carbon dioxide would be removed during respiration except when the tank reserved for the administration of carbon dioxide was used.

Gas analysis. Blood gases were determined in duplicate by the method of Van Slyke and Neill. Oxygen content was determined in $1.0 \mathrm{cc}$. samples of heparinized whole blood taken under oil; carbon dioxide in $0.5 \mathrm{cc}$. serum.

At times mixtures of inspired gases were made up 

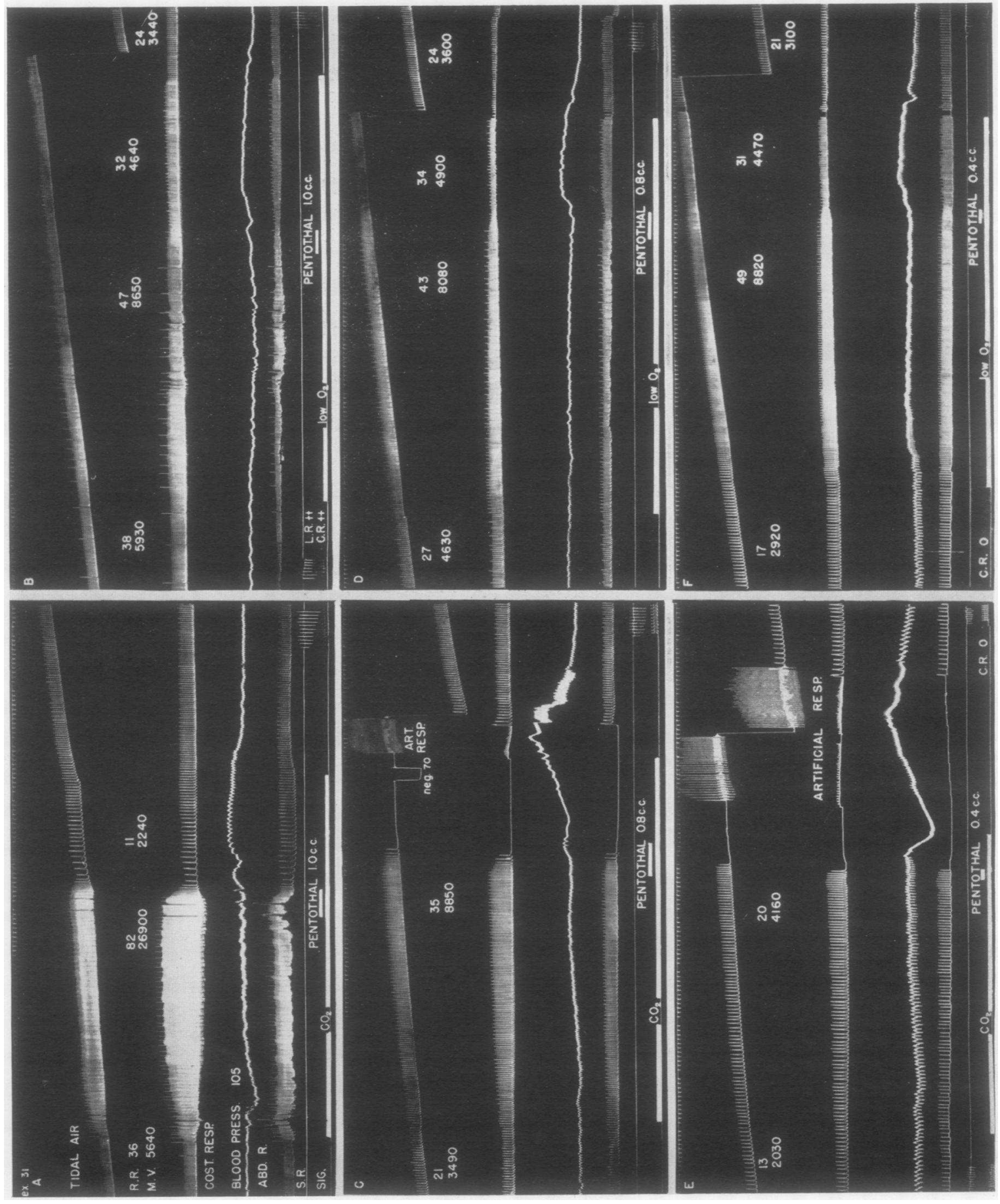

Fig. 1. Pentothal (5 Per Cent Solution) Anesthesia

In the records an upstroke corresponds to inspiration. Read from left to right. Time marker at 5-second intervals with minutes indicated. To avoid including otherwise uninteresting portions of records resulting from interference with respiration caused by sciatic stimulation, the reflex response records have been moved from nearby parts of the record. Doses are totals administered at a given time in all cases. Except as specified, the animal breathed room air. Twelve per cent carbon dioxide was used. "Low oxygen" refers to 5 per cent oxygen. The base line for blood pressure is the signal line. Weight of dog $9.8 \mathrm{kgm}$. 
specially. At other times the following mixtures were employed: In one tank 12 per cent carbon dioxide was mixed with 30 per cent oxygen and 58 per cent nitrogen. In another tank 9 per cent oxygen was mixed with 91 per cent nitrogen. The composition of the inspired gases was determined at intervals in the Henderson modification of Haldane's apparatus.

\section{RESULTS}

Although the barbiturates have been in widespread clinical use for many years, and for a considerable number of years have been used for general anesthesia, it is a curious fact that relatively little attention has been given to a consideration of the conditions which enhance the toxicity of these agents ; yet, the statement is almost axiomatic that a great hazard of the use of the barbiturates is their variability of action. Doubtless many still unknown factors are involved in this variability. Several conditions are encountered clinically which increase the toxicity of these agents: (1) gross overdosage followed by respiratory failure when the blood gases are normal, at least at first; (2) the respiratory response to the barbiturates when the blood oxygen content is low; (3) the respiratory response to the barbiturates when the blood oxygen content is high; (4) respiratory alteration and failure following administration of the drugs when the carbon dioxide content is high; (5) respiratory failure under a combination of (2) and (4) above; and, finally, (6) respiratory failure as a result of positive pressure in the airway and the breathing of 100 per cent oxygen. These conditions will be illustrated by representative examples taken from the 43 experiments.

(1) It hardly seems necessary to illustrate the production of respiratory failure by gross overdosage with barbiturates when the blood gases are initially within normal limits, for everyone who has employed these agents to any considerable extent experimentally or clinically has demonstrated this effect.

(2) The respiratory response to low oxygen is particularly interesting under the barbiturates. This has been discussed in detail by Moyer and Beecher $(8,9)$. For present purposes, this can be illustrated by Figure 1, B, D, F, and Figure 2 . In Figure 1, Sections $B, D$, and $F$ represent, respectively, light, moderately deep and deep barbiturate anesthesia. (Note the sciatic reflex evoked

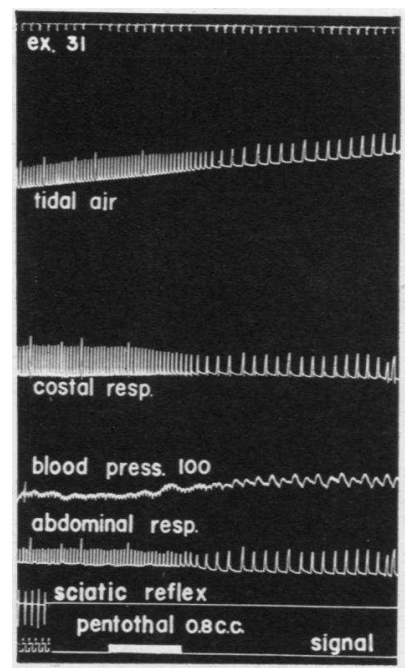

Fig. 1', D'. Pentothal (5 Per Cent Solution) Anesthesia

Details are as for Figure 1

by stimulation.) The responses of the pulmonary ventilation to four minutes of breathing 5 per cent oxygen, as well as the effects on ventilation of small doses of pentothal, are tabulated here:

TABLE I

Weight of dog: $9.8 \mathrm{kgm}$.; pentothal 5 per cent intravenously

\begin{tabular}{|c|c|c|c|c|c|}
\hline \multirow[b]{2}{*}{ Figure } & \multirow[b]{2}{*}{ Section } & \multirow[b]{2}{*}{ Depth of anesthesia } & \multicolumn{3}{|c|}{$\begin{array}{l}\text { Pulmonary minute volume of } \\
\text { ventilation }\end{array}$} \\
\hline & & & Initial & $\begin{array}{l}\text { After } \\
4 \text { min- } \\
\text { utes } \\
\text { on } \\
5 \% \mathrm{O}_{2}\end{array}$ & $\begin{array}{c}\text { Immediately } \\
\text { after } \\
\text { additional } \\
5 \% \\
\text { pentothal }\end{array}$ \\
\hline 1 & B & Light & 5930 & 8650 & $4640[1.0 \mathrm{cc}]$. \\
\hline 1 & $\mathrm{D}$ & Moderately deep & 4680 & 8080 & $4900[0.8 \mathrm{cc}]$. \\
\hline 1 & $\mathrm{~F}$ & Deep & 2920 & 8820 & $4470[0.4 \mathrm{cc}]$. \\
\hline
\end{tabular}

These figures are presented for illustrative purposes only and are not to be construed as representing precise changes to be encountered on all occasions. These figures show, however, the general fact that, over a wide range of anesthesia, low oxygen in the inspired air effects a great increase in pulmonary ventilation. It is interesting to observe in passing that, although the initial minute volumes were progressively smaller with increasing depth of anesthesia, the low oxygen produced the same final effect, that is, the ventilation rose to the same level in each case, regardless of where it had started from. This will be considered in the 

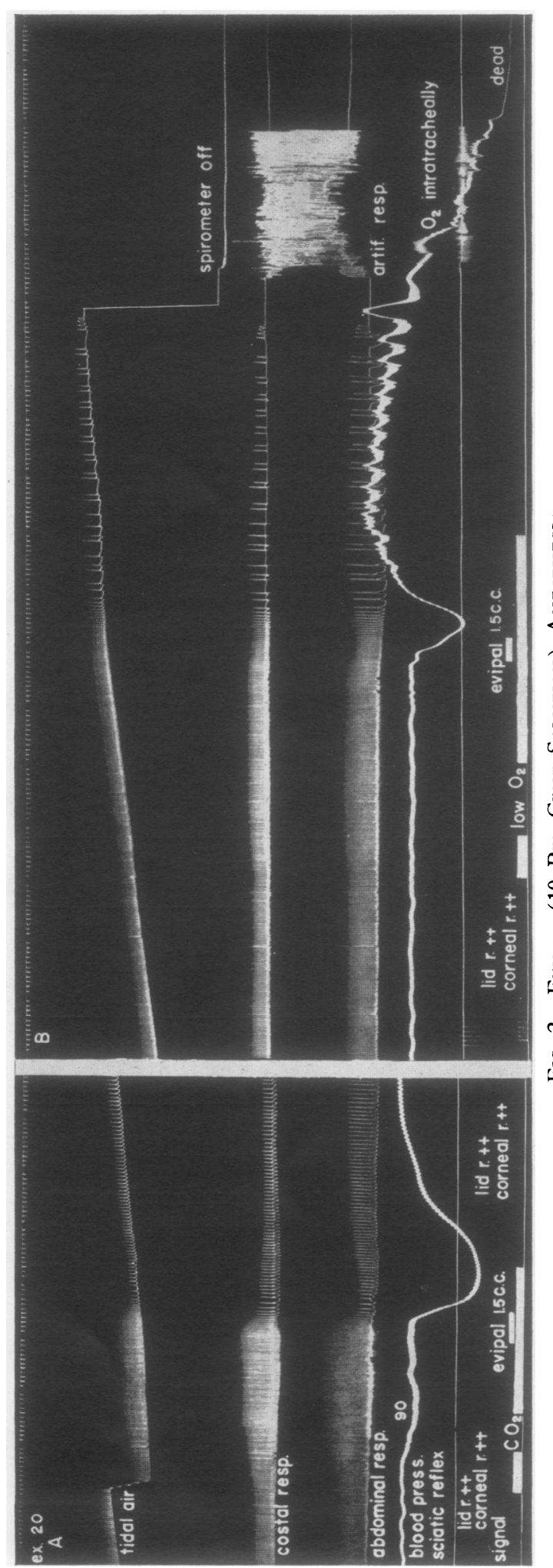

discussion. Table I contains further information of general importance: With increasing depth of anesthesia, smaller and smaller doses of drug will be necessary to produce a given reduction in ventilation in the presence of low oxygen stimulation. Under deep anesthesia, 40 per cent of the dose used in light anesthesia effected the same reduction in minute volume. (The initial ventilation under the deep anesthesia had not fallen lower than approximately $3000 \mathrm{cc}$. per minute; this ordinarily can be considered as adequate to keep the blood carbon dioxide level within normal limits, so it seems unlikely that any abnormal accumulation of carbon clioxide was present in the blood.) Notwithstanding the important stimulation of low oxygen, increasingly greater effects will be produced by given doses of bartiturate as the anesthesia deepens.

Inasmuch as a severe degree of oxygen shortage will of itself produce many of the signs of anesthesia, it is not surprising that a point will ultimately be reached where a dose of barbiturate that would not ordinarily have serious effect will, during low oxygen administration, produce a fatal result. This effect of low oxygen is illustrated in the lightly anesthetized animal whose record is shown in Figure 2, B. Evipal was the agent employed. Here, vigorous artificial respiration promptly instituted with high oxygen in the airway could not reverse the process, even though the heart continued to function for a considerable time after artificial respiration was instituted, as shown in the tracing. The earlier administration of the same dose, even in conjunction with a toxic concentration of carbon dioxide, had no serious effect (Figure 2, A). Sufficient time was allowed to elapse before the final barbiturate injection was made so that the animals were at essentially the same levels of anesthesia in Sections A and B. This, of course, must not be construed as indicating that, under all circumstances, the percentage of low oxygen employed here is more toxic than the carbon dioxide concentration used. In fact, Figure 1 nicely demonstrates that, under the circumstances of that experiment, the concentration of carbon dioxide used was more depressant than the 5 per cent oxygen with which it was compared. Figure 2 is of use in illustrating that a severe degree of oxygen shortage in conjunction with a not ordinarily dangerous dose of the barbiturate can 


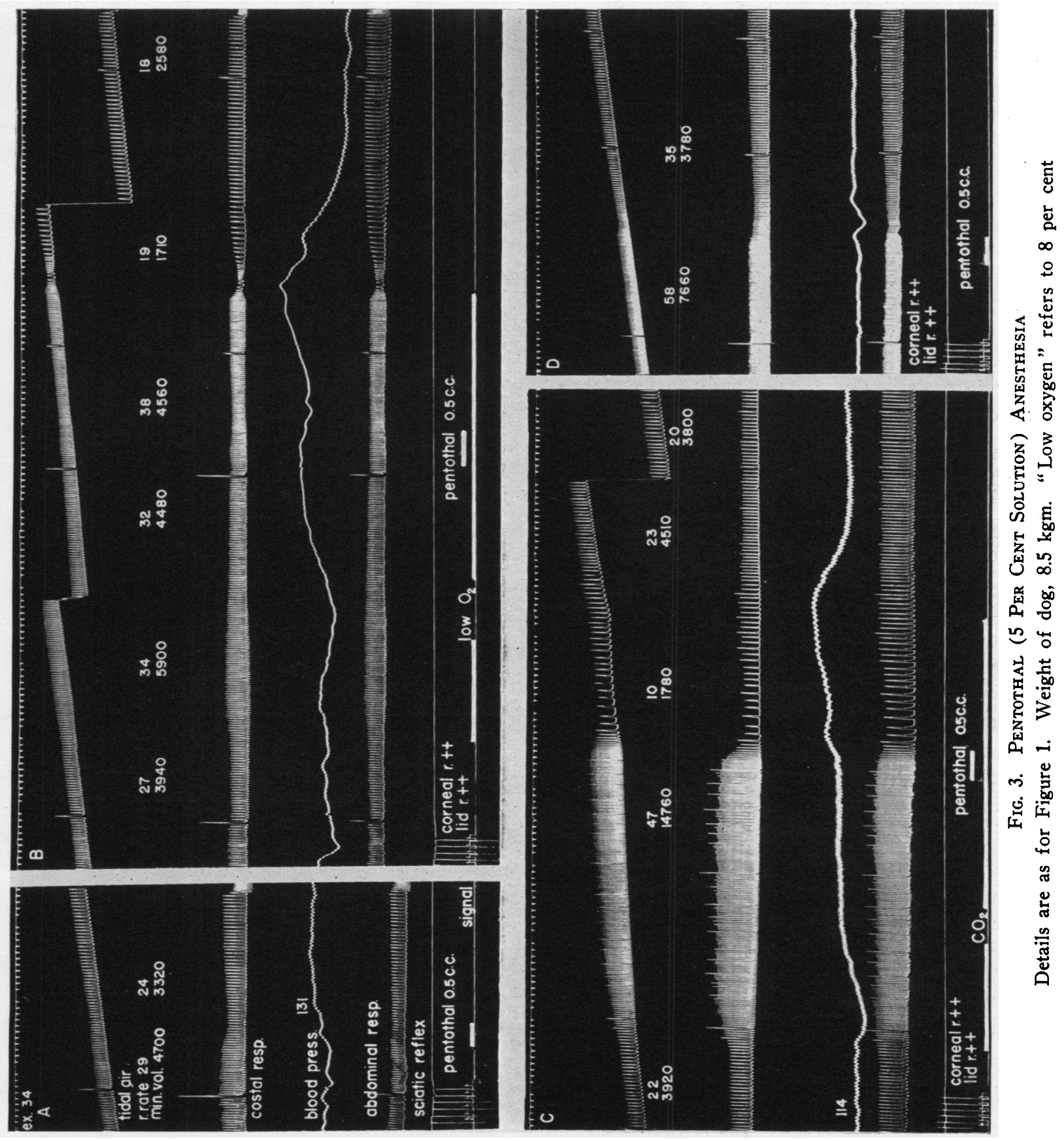


produce a fatal result even in a lightly anesthetized subject.

It is apparent from the clata already presented that low oxygen has a stimulating action on the respiration over a wide range of anesthesia depth. It is also evident that, even when the subject is in good condition and only lightly anesthetized, the combination of low oxygen and modest closage of barbiturate can produce a particularly malignant form of respiratory failure, one that is irreversible even when artificial respiration is promptly instituted and oxygen administered. It is important to emphasize. therefore, that low oxygen can first mask barbiturate depression and later add to the total depression. The masking effect is brought out in Figure 1, at the ends of Sections B, D. F, where sharp falls in ventilation are shown when the low oxygen is discontinued and room air is resumed. Figure 3 also illustrates the masking effect. Here, the $\operatorname{dog}$ weighed $8.5 \mathrm{kgm}$. Five per cent pentothal was administered intravenously. In Section A, $0.5 \mathrm{cc}$. (total close, at that injection) in the lightly anesthetized animal altered the minute volume of respiration from $4700 \mathrm{cc}$. to $3320 \mathrm{cc}$. on room air. The rate was slowed from 29 to 24 per minute. A little later, when the animal had returned to about the same light level of anesthesia. it was shifted from room air to 8 per cent oxygen in the inspired air. The initial ventilation was $3940 \mathrm{cc}$., the rate 27 . After four minutes on low oxygen this had changed to $4480 \mathrm{cc}$., with a rate of 32. At this point the same dose of pentothal used initially, $0.5 \mathrm{cc}$., was injected. Although the rate increased appreciably, from 32 to 38 , the minute ventilation now was unchanged at $4560 \mathrm{cc}$. per minute; this contrasts sharply with the initial result. Clinically, one could not have detected any depressant effect of this second dose of pentothal. The respiration, unchanged in minute volume, increased a little in rate but would not have suggested a depressant effect of the pentothal; the blood pressure was not significantly altered by the agent. Yet it is clear from the earlier Section A and the later Section D that this dose of pentothal would, with a normal concentration of oxygen in the inspired air, have produced respiratory depression. In section B this effect was masked by the low oxygen. This masking effect becomes evident only when the hypoxia is relieved by substituting room air for the low oxygen. The truly clepres- sant effect then becomes obvious. In the example at hand the minute volume of $4560 \mathrm{cc}$. fell at once to $1710 \mathrm{cc}$; the blond pressure declined rapidly. indicating that it had been maintained at its level by anoxia. The great sensitivity of these responses is indicated by the considerable effects produced under circumstances of normal oxygen intake by a very small close of barbiturate on the one hand, and by the great depression of respiratory exchange effected by the shift from 8 per cent oxygen to room air on the other hand.

(3) The depressant effect of low oxygen was mentioned in the preceding section, and data were presented to indicate how serious the masking of barbiturate depression by low oxygen might be. It will now be shown that high oxygen during barbiturate anesthesia can also have serious consequences. The fact that a high arterial oxygen tension could effect a depressant action under barbiturates and certain other agents has long been known. Mosso ( 7 ), Henderson (5), Marshall and Rosenfeld (6), and others have observed it. Figure 4 demonstrates that this effect can be lethal when evipal is the anesthetic agent.

TABLE II

Weight of $\operatorname{dog} 11.3 \mathrm{kgm}$.

\begin{tabular}{|c|c|c|c|c|c|c|}
\hline Time & Inspired & $\begin{array}{l}\text { Color of } \\
\text { mucous } \\
\text { membranes }\end{array}$ & $\begin{array}{c}\text { Arterial } \\
\text { oxygen } \\
\text { content }\end{array}$ & $\begin{array}{c}\text { Arterial } \\
\mathrm{CO}_{2} \\
\text { content }\end{array}$ & Rate & $\begin{array}{l}\text { Minute } \\
\text { venti- } \\
\text { lation }\end{array}$ \\
\hline $1: 17$ p.m. & Room air & Good & $\begin{array}{c}\text { volume } \\
\text { per cent } \\
15.5\end{array}$ & $\begin{array}{c}\text { volume } \\
\text { per cent } \\
49.8\end{array}$ & 37 & 4880 \\
\hline \multicolumn{7}{|l|}{ 1:22 p.m. } \\
\hline 1:23 p.m. & $10 c_{c}^{c} \mathrm{O}_{2}$ & & & & 28 & 3220 \\
\hline 1:25 p.m. & & & & & 31 & 3600 \\
\hline 1:29 p.m. & & & 17.3 & 51.2 & & \\
\hline $2: 27$ p.m. & Room air & Very cyanotic & 7.0 & 69.5 & 12 & 1290 \\
\hline 2:28 p.m. & $100 \% \mathrm{O}_{2}$ & & & & & \\
\hline 2:29 p.m. & & Cyanosis much less & & & 3 & 320 \\
\hline 2:30 p.m. & Infrequent gasps & & 4.8 & 78.3 & 0 & \\
\hline 2:38 p.m. & Death & & & & & \\
\hline
\end{tabular}

In Figure 4, A, the immediate effect of 100 per cent oxygen, even though the color of the mucous membranes was good, was to lower the rate from 37 to 28 and the ventilation from $4880 \mathrm{cc}$. to 3220 cc., with small blood changes in oxygen and carbon dioxide content. Later, when the animal was deeply anesthetized (sciatic stimulation produced a visible but not recorded response), the blood 

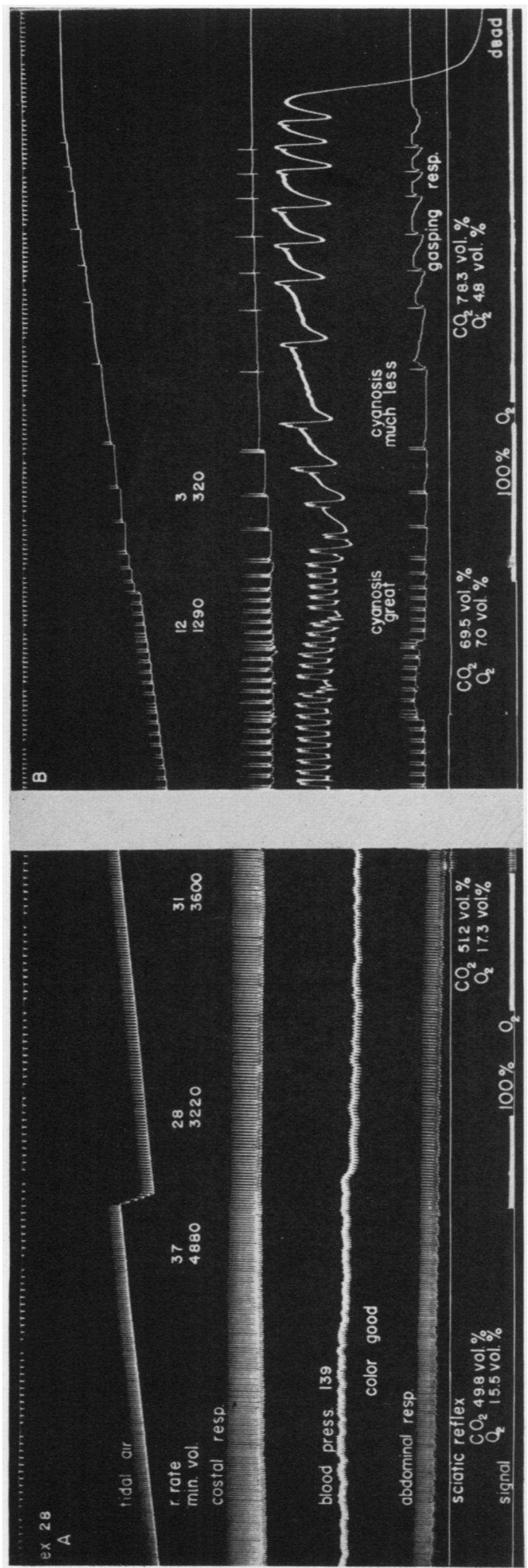

oxygen seriously low, and the carbon dioxide content abnormally high, 100 per cent oxygen produced a distinct improvement in the animal's color ; yet the respiratory rate, concomitant with the obvious improvement in oxygenation of the blood, dropped at once from 12 to 3 and quickly failed completely, although the heart continued to beat for at least a minute and a half following the last gasp.

(4) Respiratory alteration and failure following administration of barbiturates when the blood carbon dioxide content is high is shown in Figure $1, \mathrm{~A}, \mathrm{C},{ }^{3} \mathrm{E}$. These three sections represent light, moderately deep and deep anesthesia. (Note the sciatic reflex responses.) The dog used in this experiment weighed $9.8 \mathrm{kgm}$. Pentothal in 5 per cent solution was the anesthetic agent.

TABLE III

\begin{tabular}{|c|c|c|c|c|c|}
\hline \multirow[b]{2}{*}{ Figure } & \multirow[b]{2}{*}{ Time } & \multirow[b]{2}{*}{$\begin{array}{c}\text { Depth } \\
\text { of } \\
\text { anesthesia }\end{array}$} & \multicolumn{3}{|c|}{$\begin{array}{l}\text { Pulmonary minute volume } \\
\text { of ventilation }\end{array}$} \\
\hline & & & Initial & $\begin{array}{c}\text { After } \\
4 \text { min- } \\
\text { utes on } \\
12 \% \\
\mathrm{CO}_{2}\end{array}$ & $\begin{array}{c}\text { Imme- } \\
\text { diately } \\
\text { after } \\
\text { additional } \\
\text { pentothal }\end{array}$ \\
\hline $\begin{array}{l}\text { 1. } \mathrm{A} \\
1, \mathrm{C} \\
1, \mathrm{E}\end{array}$ & $\begin{array}{l}11: 13 \text { a.m. } \\
12: 10 \text { p.m. } \\
1: 32 \text { p.m. }\end{array}$ & $\begin{array}{l}\text { Light } \\
\text { Moderately deep } \\
\text { Deep }\end{array}$ & $\begin{array}{l}5,640 \\
3,490 \\
2,030\end{array}$ & $\begin{array}{r}26,900 \\
8,850 \\
4,160\end{array}$ & $\begin{array}{r}2,240[1.0 \mathrm{cc} .] \\
0[0.8 \mathrm{cc} .] \\
0[0.4 \mathrm{cc} .]\end{array}$ \\
\hline $1, D^{\prime}$ & 12:36 p.m. & Moderately deep & & & [0.8 cc.] \\
\hline
\end{tabular}

In passing, it will be observed that Figure 1. A. $\mathrm{C}, \mathrm{E}$ and Table III demonstrate the gradual decrease of sensitivity of the respiratory center to a given carbon dioxide concentration in the inspired air. In Figure 1, A, four minutes of breathing 12 per cent $\mathrm{CO}_{2}$ resulted in nearly a five-fold increase in ventilation; in Figure 1, $\mathrm{C}$ the effect was half (two and one-half-fold) what it had been in Figure 1, A; in Figure 1, E, four minutes of breathing 12 per cent $\mathrm{CO}_{2}$ merely resulted in doubling the ventilation. This characteristic of the barbiturates has been discussed elsewhere by Moyer and Beecher. The point of immediate importance is that the respiratory center is less sensitive than normal to its natural stimulus, carbon dioxide. The carbon dioxide finally becomes, in

${ }^{3}$ In Figure 1, C, an example of sudden alteration of cardiac activity, probably due to heart block, can be seen. This was frequently encountered under pentothal under the circumstances of these experiments. It is being investigated further. 
fact, a depressant. Therefore, it might be expected that additional doses of the barbiturate would have a tendency to produce respiratory failure when the carbon dioxide level of the blood was high, when otherwise this would not be so. Figures 1 and $1^{\prime}, D^{\prime}$ show this to be the case. Respiratory failure is not produced in Figure 1, A by $1.0 \mathrm{cc} .5$ per cent pentothal. At a deeper level of anesthesia a smaller dose $(0.8 \mathrm{cc}$. $)$ did cause the respiration to fail. Chronologically, the doses were given as follows : 9:00 a.m., $5.0 \mathrm{cc}$. of 5 per cent pentothal ; $9: 15,1.0 \mathrm{cc}$; 9:30, $1.0 \mathrm{cc}$; 10:10. 1.0 cc.; $10: 27,1.0$ cc.; $11: 18,1.0$ cc. ; $11: 45,1.0$ cc.; $12: 00,1.0$ cc.; $12: 15,0.8$ cc.; $12: 37,0.8$ cc.

It might be argued that the respiratory failure in Figure 1, C was due to the cumulative effects of the repeated doses. That this is not so is indicated by the fact that the respiration did not fail when the same size dose was administered later while the animal was at least as deeply anesthetized as in Figure 1, C, but was not on a high carbon dioxide intake, Figure 1', $\mathrm{D}^{\prime}$ (preceding $\mathrm{D}^{\prime}$ two doses of agent in addition to those listed had been administered at fairly close intervals).

Figure 8 illustrates in an animal breathing room air the enormous increase in ventilation effected by carbon dioxide stimulation in a subject lightly anesthetized with evipal (similar to Figure 1, A). Later, at a deeper level of anesthesia, the swift production of respiratory failure by a brief exposure to the same concentration of carbon dioxide is shown. Anoxia caused the blood pressure to rise. A moderate degree of negative pressure in the airway reestablished respiration. After a minute on negative pressure, enough carbon dioxide had been washed out and the carbon dioxide depression overcome to such an extent that the respiration could continue spontaneously when the negative pressure was relieved (10).

In Figure 9, A, the animal was deeply anesthetized and breathing 100 per cent oxygen. The initial respiratory rate was 6 with a minute ventilation of $1460 \mathrm{cc}$. The sciatic reflex response is interesting, in that it was more greatly depressed than could be accomplished with evipal alone without respiratory failure. It would appear safe to conclude that the animal was already suffering from carbon dioxide depression. If this were true, administration of synthetic carbon dioxide should result in further depression of respiration and the sciatic reflex, not stimulation. This was the case. After three minutes of breathing 12 per cent carbon dioxide, the respiratory rate had slowed to 2 per minute, and the minute volume was reduced to $570 \mathrm{cc}$. At the time the carbon dioxide administration was discontinued, the rate of respiration was slowing rapidly, and almost at once failed completely. Following the respiratory failure, electrical stimulation of the sciatic nerve reestablished respiration. With the first stimuli no muscle response was recorded. The respiration resulting from the sciatic stimulation undoubtedly washed out a considerable part of the carbon dioxide which had been depressing the subject. The reappearance and the subsequent small but definite increase in the record of the reflex response support this.

The animal was still deeply anesthetized, however, and the respirations were only 4 per minute with a minute ventilation of $1060 \mathrm{cc}$. when the vagi were blocked with cold. While the rate remained the same, the amplitude of respiratory excursion increased to result in a minute volume of 1480 cc. Carbon dioxide was administered again, and again respiration failed, this time with the vagi blocked.

In Section B of Figure 9, recorded an hour and a half following Section A, the animal had become considerably lighter. (Observe the sciatic and the eye reflexes.) The carbon dioxide stimulus now increased the ventilation from $2140 \mathrm{cc}$. per minute to $3040 \mathrm{cc}$., rather than depressed it as it had in Section A. This was also true when the vagi were blocked. In A, with anesthesia deep, carbon dioxide depressed respiration; in $\mathrm{B}$, with anesthesia lighter, respiration was stimulated. These changes occurred notwithstanding vagal blocks. These results were confirmed in other cases. It must be concluded from Figures 1, A, C, E, 8, and 9 that a high concentration of carbon dioxide in the inspired air enhances the depressant action of a given dose of barbiturate; this effect is increasingly great with deepening anesthesia.

(5) The early effect of low oxygen in masking the barbiturate depression, and the acutely fatal effects of severe anoxia during barbiturate anesthesia, have been demonstrated. The increased depression caused by given small doses of barbiturates when the blood carbon dioxide level is high has also been shown. It is reasonable to suppose 


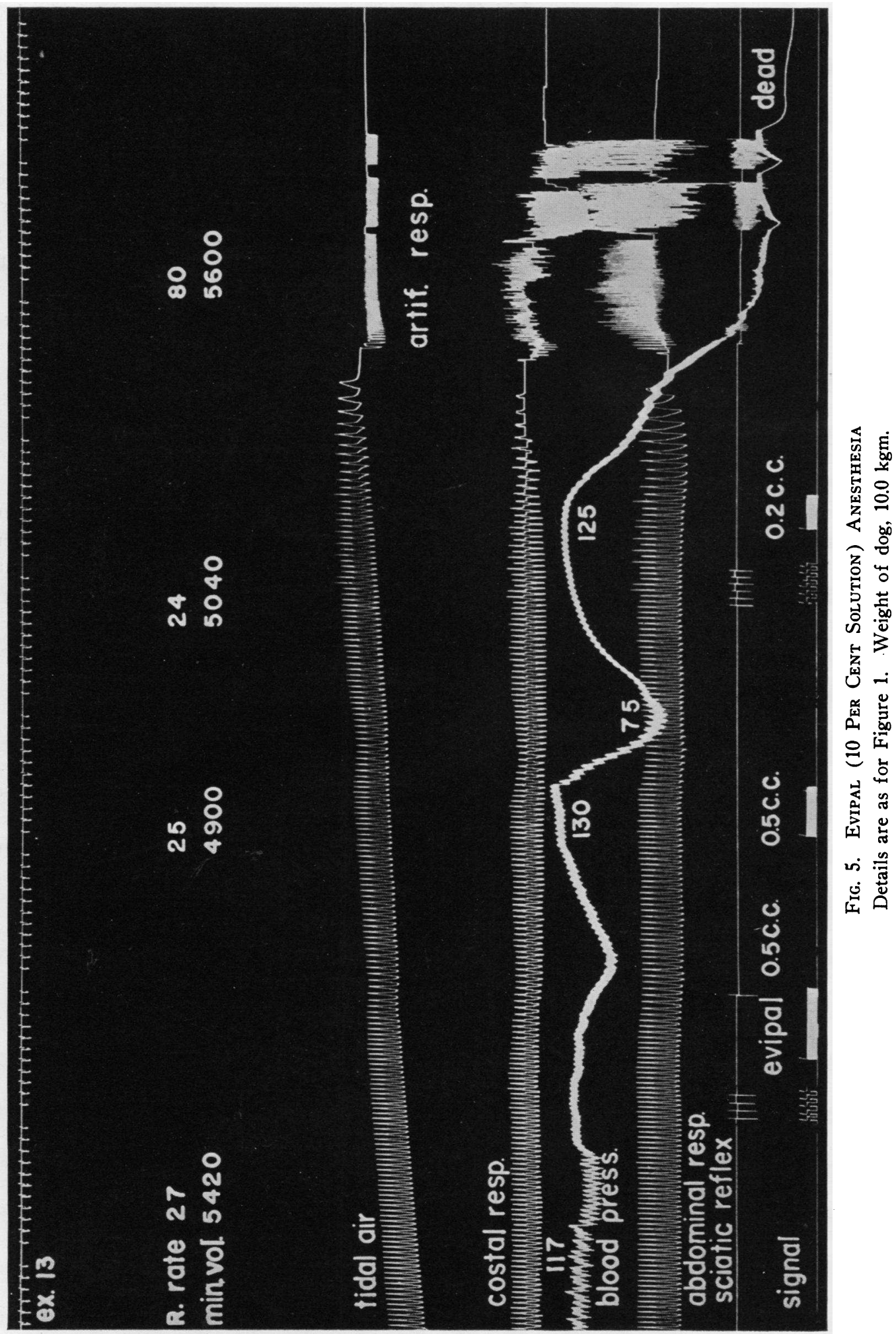


that the combined effects of low oxygen and high carbon dioxide in the arterial blood might be peculiarly serious. Such is the case. Figure 5 demonstrates a result of this combination. During the course of this experiment on a healthy, approximately one-year-old, $10 \mathrm{kgm}$. dog. it was observed that the Tissot valve in the expiratory half circuit had become stuck in the open position, with the effect that the dead space was greatly increased and no proper circulation of air took place through the soda lime. The animal was thus subjected to gradually increasing oxygen shortage and a gradual piling up of carbon clioxide. These effects were not clinically evident. An active sciatic reflex response was present and indicated that the animal was only moderately deeply anesthetized. The pulmonary ventilation was good with a respiratory rate of 27 and a minute volume of $5420 \mathrm{cc}$. The mean blood pressure was normal at $117 \mathrm{~mm}$. $\mathrm{Hg}$. Since the animal was not as deeply anesthetized as desired, it was decided to give more of the 10 per cent evipal solution; $0.5 \mathrm{cc}$. (total dose, not per $\mathrm{kgm}$.) was administered. The changes produced in the respiration were so slight and so fleeting that they probably would not have been detected clinically. One minute following the administration of the evipal the respiratory rate was 25 , the minute volume $4900 \mathrm{cc}$., and the blood pressure $130 \mathrm{~mm}$. Hg, certainly reassuring. Since the animal was still quite obviously not yet deeply anesthetized, $0.5 \mathrm{cc}$. of the anesthetic solution was administered as shown, and again only a fleeting depression of the respiration and blood pressure was apparent. From the records obtained of these effects it is evident that the blood pressure suffered more severely than in the first instance. Yet it remained at a fairly low level for only about 20 seconds. It is hardly likely that this brief dip would have been detected clinically. If it had been, by the time the anesthetist checked it recovery would have taken place, and the first low reading would have been put down as error. The animal was still not deeply anesthetized, as shown by the record of the sciatic reflex just before the third dose was administered. At this time the respiratory rate was 24 , the minute volume of respiration $5040 \mathrm{cc}$. and the blood pressure 125 mm. Hg. Certainly nothing was present that could have been detected clinically and that might have warned of impending disaster. Since the animal was not yet as deeply anesthetized as desired, it was decided to administer a further small dose of evipal, $0.2 \mathrm{cc}$. The response to this was swift and completely unexpected. The respiration slowed at once and entirely failed within a minute. The blood pressure fell abruptly. Artificial respiration was promptly started and ventilation at the rate of $5600 \mathrm{cc}$. per minute was carried out. The heart continued to beat for two minutes following the respiratory failure and then stopped despite the vigorous artificial respiration. The mechanism of the death here and its clinical significance will be considered in the discussion.

Figure 4. B, also presents an example of death under conditions of high blood carbon dioxide and low blood oxygen. This will be discussed in conjunction with the example shown in Figure 5. already described.

(6) Figure 6 shows, during the breathing of 100 per cent oxygen, the increasing effect of a moderate elevation of pressure in the airway (5.0 $\mathrm{cm}$. $\left.\mathrm{H}_{2} \mathrm{O}\right)$ with deepening anesthesia, indicated by the diminution in the sciatic reflex response. In $\mathrm{D}$, the increase in pressure by $5.0 \mathrm{~cm}$. $\mathrm{H}_{2} \mathrm{O}$ produced respiratory failure. The stimulating effect of negative pressure $\left(5.0 \mathrm{~cm} . \mathrm{H}_{2} \mathrm{O}\right)$ is also shown. In $\mathrm{E}$, the respiratory depression was so great that respiration failed even under atmospheric pressure; sciatic stimulation produced two breaths. Negative pressure caused the respiratory activity to be resumed. Figure 7 demonstrates that the apnea produced by positive pressure is occasioned by a reflex mediated through the vagus; vagal cold blocks permitted the respiration to be resumed. Figure 8, B, illustrates the power of negative pressure to reestablish respiration which has failed as a result of carbon dioxide depression.

\section{DISCUSSION}

The factors responsible for the variability of response to a given dose of barbiturate, from one patient to another or in the same patient on different occasions, have in the main been obscure. It will be apparent from the data presented and the discussion to follow, that variations in oxygen supply and carbon dioxide content of tissues and blood can exert a powerful influence on the responses resulting from given doses of barbiturates. However, before these matters are dealt with, it should be observed in passing that a reciprocal 

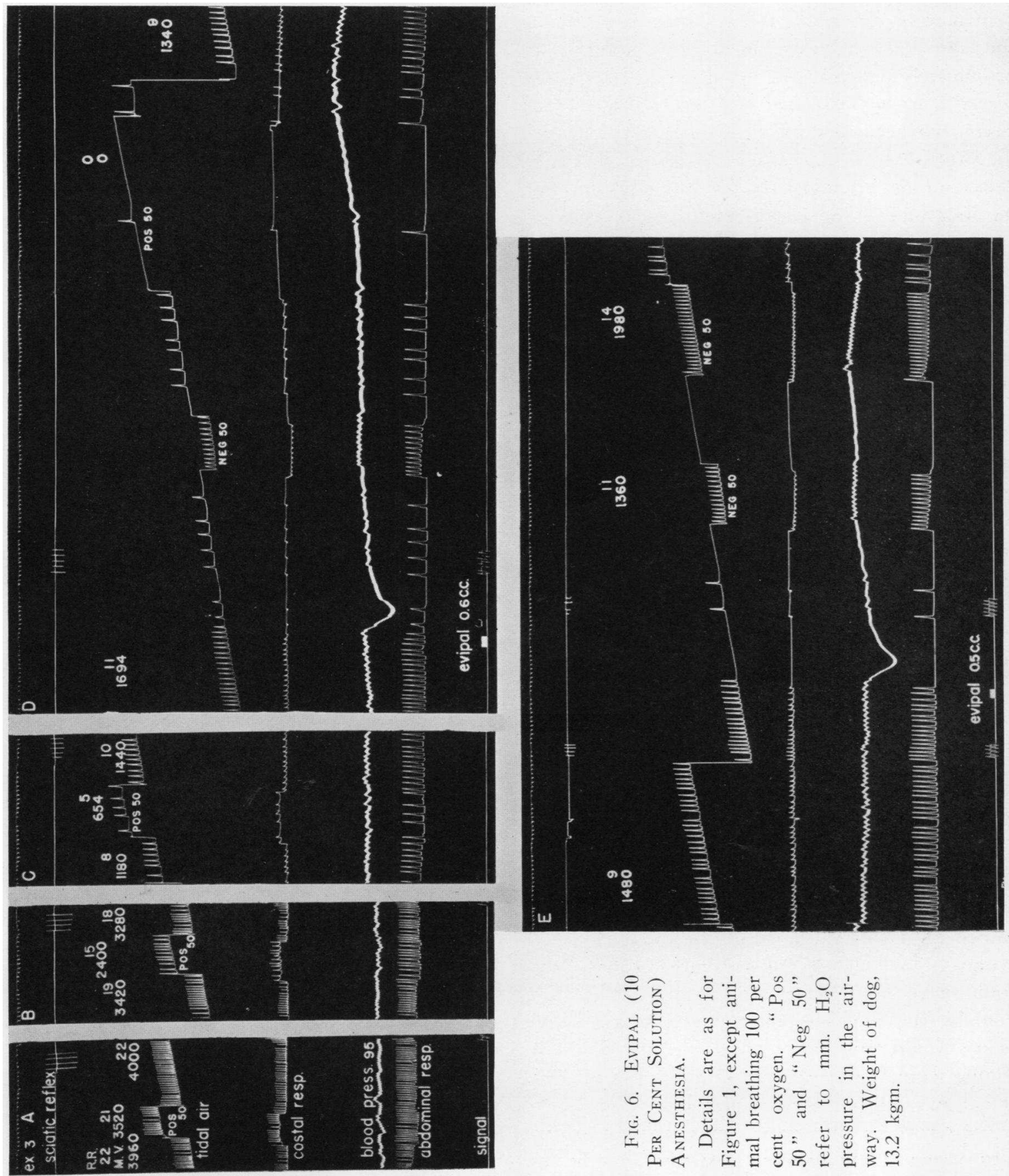


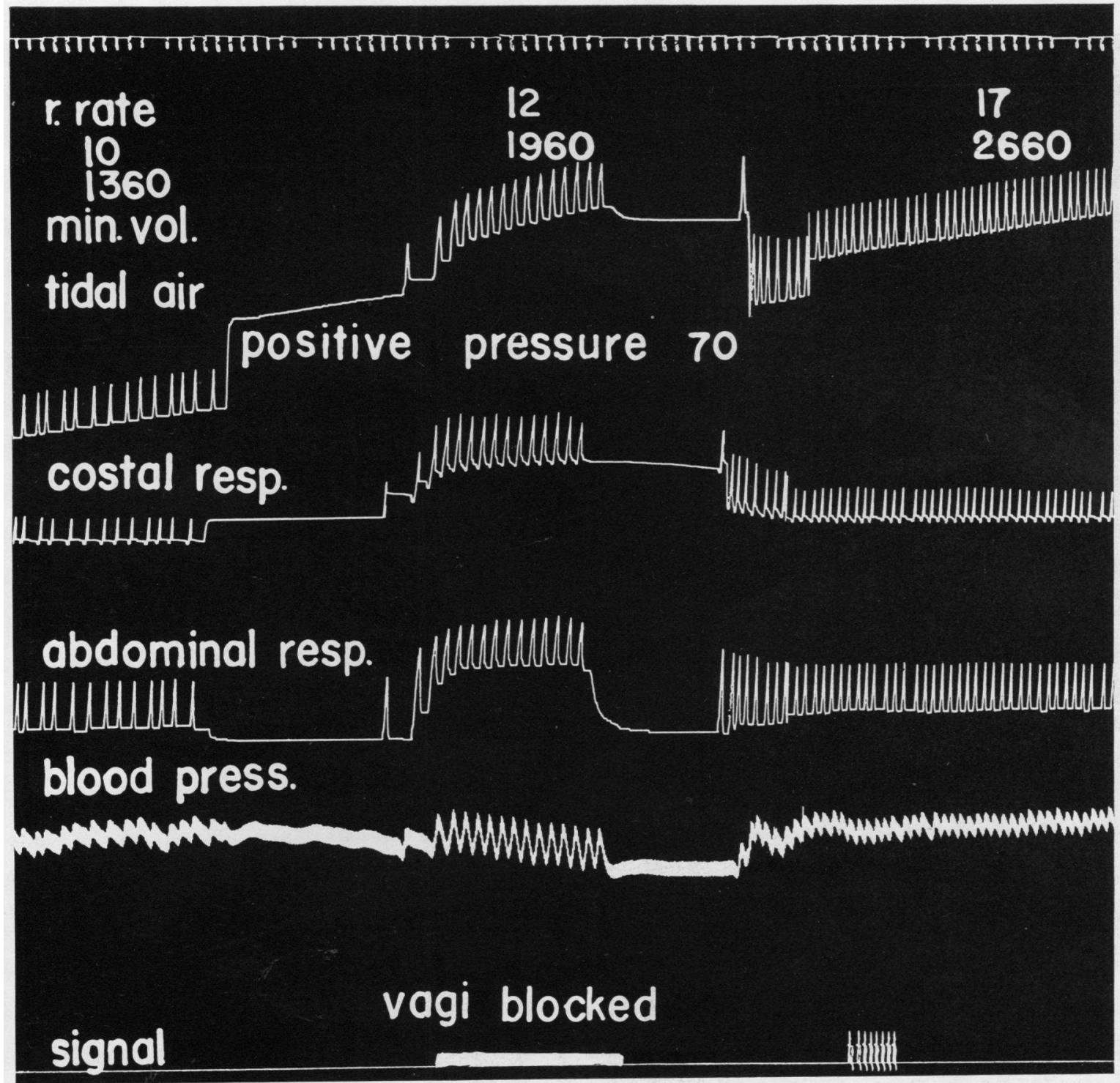

Fig. 7. Evipal (10 Per Cent Solution) Anesthesia

Details are as for Figure 1, except on 100 per cent oxygen. Weight of $\log , 11 \mathrm{kgm}$.

relationship between closage and pulmonary ventilation is apparent. It is plain that increasing dosage will lead to rather early respiratory failure. This holds both for evipal and pentothal. The tendency is demonstrated for the latter in Figures $1, \mathrm{~B}, \mathrm{D}, \mathrm{F}$, where in round numbers the initial ventilation under light anesthesia was 6 liters per minute, under moderately deep anesthesia 4.5 , and under deep anesthesia 3 . In these 3 cases the effective respiratory impulses from the center have been reduced from 38 to 27 to 17 per minute.
The center loses much of its sensitivity to its major normal stimulus, carbon dioxide. This is demonstrated in Figure 1, A, C, E. In round numbers this is reflected in a decrease in total response above "normal" to the "standard" carbon dioxide stimulus, from 21 liters per minute to 5 to 2 . Figure $8, \mathrm{~A}, \mathrm{~B}$, illustrates the change from a tremendous stimulation to a frank depression with respiratory failure in response to a given concentration of carbon dioxide. Evipal was the anesthetic in this case. 

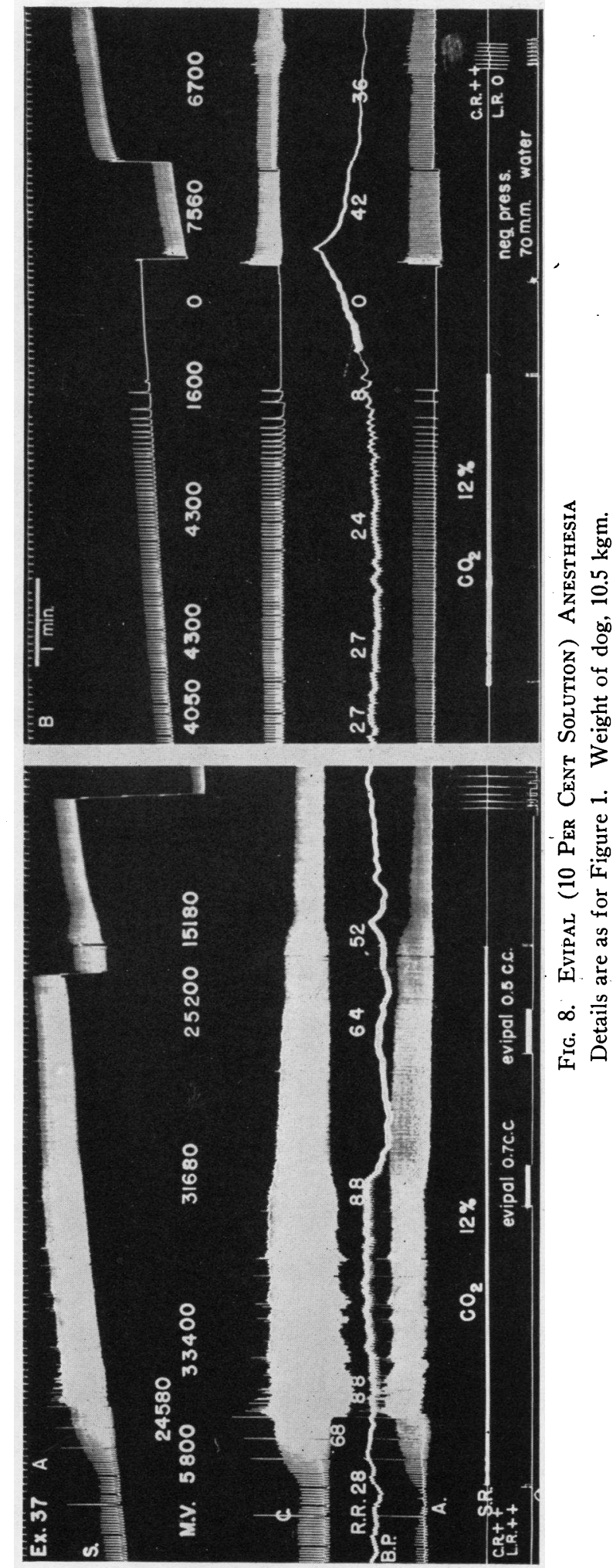

While the barbiturates rapidly diminish and finally eliminate the sensitivity of the respiratory center to carbon dioxide, the response to low oxygen is reduced very little as shown in Figure 1 and Table I. The same final minute volume response to low oxygen at the three widely differing levels of anesthesia suggests that, under moderate to deep barbiturate anesthesia, the respiration is chiefly maintained by mechanisms which are activated by low oxygen stimulation, which is in agreement with Schmidt (11), Cordier and Heymans (2), and Marshall and Rosenfeld (6). As demonstrated by Moyer and Beecher (8), central stimulation of low oxygen is important, although only under very light anesthesia, as well as peripheral stimulation, arising chiefly in the carotid and aortic bodies as shown by Heymans and others. It is interesting to observe that even at the deep level of anesthesia no loss of sensitivity to the low oxygen concentration employed is apparent, although the initial ventilations were in each case progressively smaller, presumably due to central depression by the barbiturate, resulting in the loss of sensitivity to the normal central stimulus, carbon dioxide.

The increasing effectiveness of small doses of the barbiturates is illustrated in Figure 1 and Table I. It will be recalled in the case of the volatile anesthetic agents, ether for example, that the concentration of this agent in the blood required to produce loss of consciousness is only one-third of that necessary to produce light surgical anesthesia, yet a small increase in ether concentration in the blood after the surgical level has been reached will carry the subject from light to dangerously deep anesthesia. In the case of the volatile agents, this clinical effect depends upon the approach of saturation of the lipoid structures with the fat-soluble anesthetic agents. Whether a comparable "saturation" occurs in the case of the barbiturates is not known. If such were the case, it would be of great interest to know where the barbiturates are concentrated.

Inasmuch as the short-lasting barbiturates, evipal and pentothal, depress the central drive mechanism more than the reflex drives of respiration, the masking of serious barbiturate depression by oxygen tensions that are below normal is not surprising in view of the fact that low oxygen stimulates breathing reflexly (excepting, of course, those 


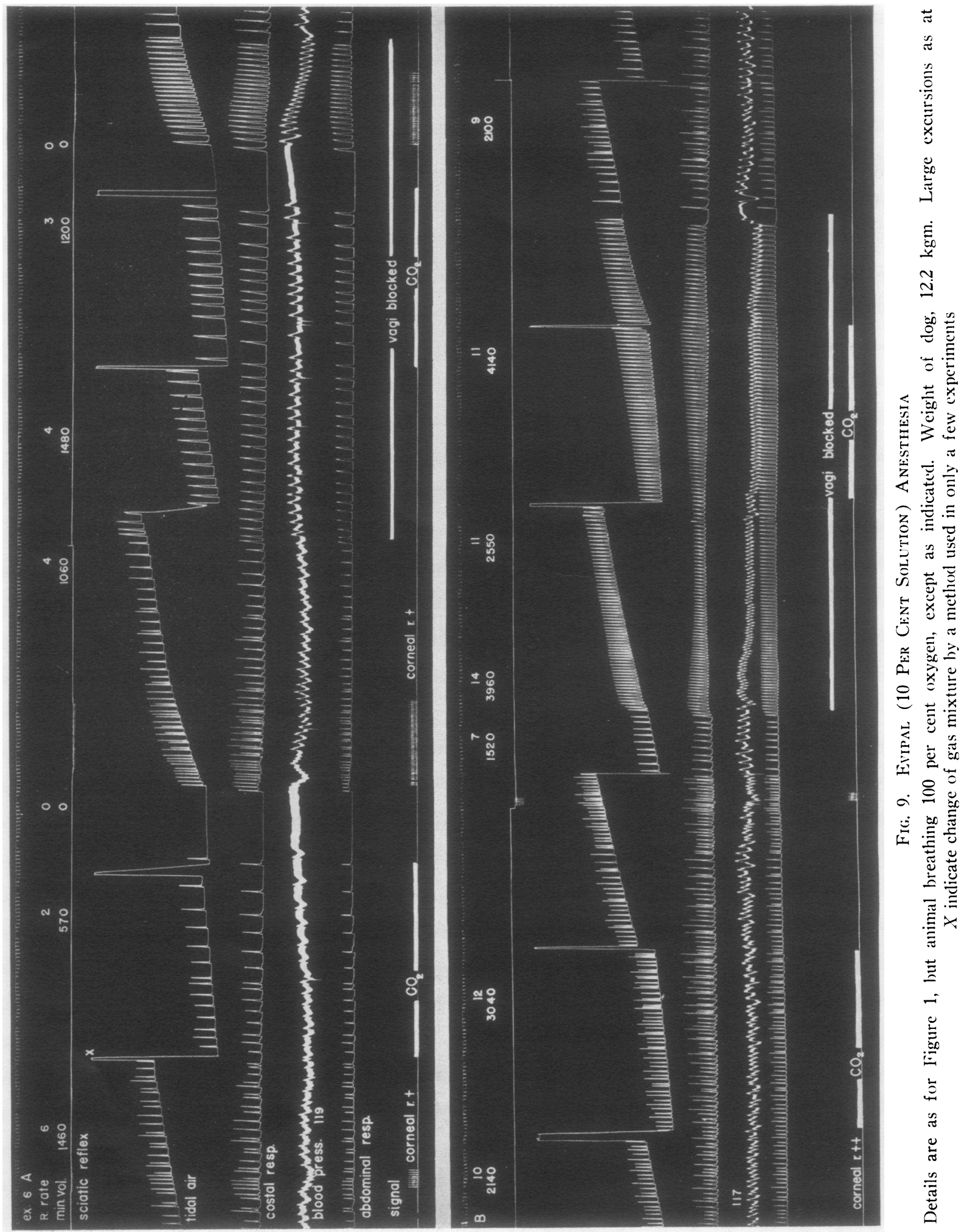


cases where the central sensitivity to $\mathrm{cH}^{+}$is very high and carotid and aortic sensitivity is very low). The clinical implications of this masking are so obvious that they need no discussion. A sudden increase in the oxygen content of the inspired air, even though it be slight, reveals, by virtue of the associated reduction of chemoreflex stimulation, the depressant action of the barbiturate (Figures 1, B, D, F and 3, B). Such respiratory depression, coupled with the already demonstrated loss of sensitivity of the respiratory center to carbon dioxide, can lead to a particularly serious form of depression. The sequence of events is probably as follows: Barbiturate anesthesia is administered to the subject. The sensitivity of the center to $\mathrm{H}^{+}$is reduced. After the center's $\mathrm{H}^{+}$sensitivity is greatly impaired or entirely destroyed the anoxic stimuli maintain pulmonary ventilation that is dependent upon oxygen level and the effectiveness of reflex drive. The anesthetist observes that the reflex drive is inadequate to maintain proper oxygenation if the subject's color is poor and he increases the oxygen concentration in the inspired air. The carotid and aortic body stimuli set up by the low oxygen are thus decreased, as the blood oxygen content approaches normal. Loss of the low oxygen stimuli allows the true state of affairs to become apparent to the discerning observer. The subject's respirations are found to be seriously depressed as a result of the barbiturate action; however, the high concentration of oxygen in the inspired air still maintains an adequate blood color and the vasomotor status is good. During this period the subject's good color keeps attention from the fact that the respiration is not adequate as far as the excretion of carbon dioxide is concerned, for the center has lost much of its ability to respond to the high concentration of carbon dioxide in the blood. The carbon dioxide piles up until it, too, becomes a true depressant (Figure 8, B). Suddenly the respiration fails. The high carbon dioxide blood content, having first stimulated, then depresses. Blood pressure finally falls precipitously. Irreversible changes swiftly take place and, notwithstanding artificial respiration, death occurs.

The effect of low oxygen in masking the true depressant action of the barbiturate must not be considered as in itself a good thing, for the dan- gers inherent in a low oxygen intake are still present. They are too well known to need discussion. The masking effect will, of course, pass when the availability of oxygen in the tissues falls so low that the anoxia itself effects a depression. During the respiratory depression carbon dioxide piles up in the blood and tissues. In such a case, when the masked depression is carried to the breaking point, the additive effects of the depression caused by low oxygen, the depression caused by the high carbon dioxide, and the depression of the barbiturate, working together not only upon the respiratory center but upon the vasomotor center as well, swiftly produce changes which lead to death. Figure 4 illustrates the rapid failure of respiration while the blood color improved, with death due finally to a combination of low oxygen, high carbon dioxide and drug depression.

The circumstances which lead to the death of the animal pictured in Figure 5 might easily have their counterpart in the clinic (and probably often have had). Following the sudden death of a patient under barbiturate anesthesia, the statement is often heard that death was wholly unexpected and occurred without warning. The writers must admit to a considerable scepticism in the past as to the quality of the observation which allowed such statements to be made. It would seem that such an attitude is unjust, for in the laboratory at least it has repeatedly been possible to produce "sudden death without clinical warning". It is evident from Figure 5 that until the very end nothing was apparent in the condition of the only moderately deeply anesthetized subject that could have reasonably been detected clinically and have warned of impending death. This is to be explained, we believe, upon the basis just described of low oxygen masking the true depression of the barbiturate while carbon dioxide gradually accumulated to a depressant degree. The low oxygen, high carbon dioxide and the final, although very small, dose of barbiturate produced a depression of the respiratory and vasomotor centers which could not be overcome by vigorous artificial respiration.

The respiratory depression and failure produced by relatively slight elevation of pressure in the airway under the barbiturates during the breathing of 100 per cent oxygen, as shown in Figures 6 and 7 , need further study before their 
full clinical significance can be estimated. For example, how applicable these findings are to momentary blockage of the airway by the tongue and to the probable alterations of vagal proprioceptive reflex balance of asthmatics is not clear. If this type of reflex respiratory failure is produced in asthmatics during barbiturate anesthesia, a contraindication to the use of these barbiturate agents would be evident on this basis alone, and a more complete explanation would be at hand for the vague clinical impression that barbiturate anesthesia should not be administered to asthmatics.

However, there is no need to speculate on this unexplored aspect of the asthmatic problem, for enough objective data are at hand to indicate how hazardous the use of these agents in asthmatics can be. The dangers of oxygen want and a high blood carbon dioxide level have been shown. These are the very conditions encountered in asthma. The alveoli are ventilated poorly and some of them not at all. The normal gaseous exchange is grossly interfered with. The alveolar air contains a high percentage of carbon dioxide and a low percentage of oxygen, and the blood contains a low oxygen content with retention of carbon dioxide. The tendency of carbon dioxide to pile up in the blood of the asthmatic is accelerated by the impairment of the sensitivity of the respiratory center to carbon dioxide by the barbiturate. As the barbiturates are administered, the peripheral chemoceptors activated by the low oxygen stimuli mask the overdosage present. The high carbon dioxide blood content causes the level of serious overdosage to be reached sooner than would normally be the case. Suddenly the low oxygen stimuli are no longer adequate to maintain respiration; the low oxygen becomes of itself depressant. The low oxygen depression, the carbon dioxide depression and the barbiturate depression, acting together, swiftly damage the organism. It is no wonder that asthmatic patients " do not do well" under barbiturate anesthesia.

It is evident that there is no need to add a possible vagal proprioceptive reflex tending to produce respiratory failure to the already sufficient reasons why barbiturate anesthesia in asthmatics is dangerous. Certainly the above demonstration of respiratory failure as a result of a little increase in pressure in the airway offers further cogent reason why barbiturate anesthesia should not be employed in patients who may require positive pressure anesthesia as in some types of thoracic surgery.

It follows from the remarks concerning asthma that the use of barbiturate anesthesia in emphysematous patients is ill-advised. While the tidal excursion in emphysema may be essentially normal, the residual air (as in the asthmatic) is greatly increased with corresponding decrease therein of oxygen tension and elevation of carbon dioxide to 50 to $60 \mathrm{~mm}$. $\mathrm{Hg}, 7$ to 8 per cent. The arterial blood saturation may be only a little below normal or it may go as low as 85 per cent (1). Why the gaseous exchange is impaired as much as it is in emphysema has not been completely explained. The relative insensitivity to carbon dioxide in emphysema further increases the hazard of barbiturate use. Morphine must be used with caution since it reduces the carbon dioxide sensitivity of the center.

Similar contraindications to the use of barbiturate anesthesia are apparent in the respiratory and blood gas exchange alterations effected by cardiac disease.

In diabetes mellitus accumulation of abnormal acids is found in the blood; on being buffered by plasma bicarbonate these acids disturb the $\mathrm{H}_{2,} \mathrm{CO}_{3} / \mathrm{BHCO}_{3}$, ratio in the direction of acidemia. In uncompensated acidemia the hazards of the use of these agents are greater than in normal individuals.

Since one of the most important functions of the kidneys is the regulation of the acid-base balance of the plasma, acidemia frequently results from renal insufficiency. Therefore, the barbiturates are contraindicated for the reasons mentioned above. Factors such as these probably account for the fairly widespread reluctance to employ these barbiturates in patients with kidney disease, rather than any considerations of kidney excretion of the agents or their breakdown products, since kidney excretion does not appear to be of importance in the case of the short-lasting barbiturates.

Many other clinical conditions could be considered wherein the use of the barbiturates appears to be unwise. Such a list would include, surgical shock, among others, all conditions that result in a low blood or tissue oxygen or a high carbon dioxide blood level, or both. 


\section{SUMMARY}

The mechanisms of respiratory failure under evipal and pentothal anesthesia have been studied in experiments upon 43 dogs in order to get a better understanding of the factors involved in the variability of effect produced by given doses of the barbiturates. Three simultaneous records of respiration were made: tidal, costal and diaphragmatic, as well as a record of blood pressure. Depth of anesthesia was followed by records of the activity of a spinal reflex with frequent notes as to the state of the corneal and lid reflexes. Doubtless many still unknown factors are involved in the variability of action of these agents; however, several conditions frequently encountered clinically, which are capable of enhancing the toxic effects of the agents, are described.

Over a wide range of anesthesia, low oxygen in the inspired air effects a great increase in pulmonary ventilation. Although with increasing depth of anesthesia the initial minute volumes were progressively smaller, low oxygen produced the same final ventilation over the wide range of anesthesia studied (Figure 1, B, D, F). Even at the deep level of anesthesia considered, no loss of sensitivity to this stimulus was apparent with the oxygen concentration studied. Several demonstrations of the effect of a low oxygen tension in the blood in temporarily masking serious barbiturate depression are provided (Figures 1, B, $\mathrm{D}, \mathrm{F}$ and $3, \mathrm{~B})$. This effect is revealed by substituting room air for the low oxygen mixture being inspired. When the oxygen tension is very low it finally exerts a depressant effect which, on being added to the depressant action of the barbiturates, leads to death.

The effect of high oxygen in depressing the respiration which has been maintained in whole or in part by carotid and aortic mechanisms (activated by low oxygen) has been recognized, as far as the effect itself goes, for many years. This effect is present under evipal and pentothal. The elimination of the carotid and aortic activity by adequate oxygen tensions can be fatal (Figure 4).

Respiratory failure following the administration of relatively small doses of barbiturates when the blood carbon dioxide content is high is shown (Figure 1, C, E).
The sensitivity of the respiratory center to its normal stimulus, carbon dioxide, diminishes (Figure 1, A, C, E and Table III) and is finally lost under the barbiturates. The carbon dioxide finally becomes a serious depressant (Figure 8). A high concentration of carbon dioxide in the inspired air increases the sensitivity of the respiration to a given dose of barbiturate (Figure 1, A, C, E).

A combination of low oxygen and high carbon dioxide in the inspired air is particularly hazardous. Low oxygen masks the true depressant action of the barbiturate until later a point is reached when the low oxygen stimulation is no longer capable of supporting the respiration, but becomes itself depressant, and adds to the depressant action of the high carbon dioxide and the barbiturate, with a fatal outcome. This probably explains the "deaths without warning" described clinically (Figure 5).

The powerful influence exerted by various oxygen and carbon dioxide contents of the blood upon the response to a given dose of barbiturate is apparent. It is probable that variations in these gas tensions account in part for the well-known puzzling clinical variability of action of the barbiturates.

Respiratory depression and failure, as a result of a small elevation of pressure in the airway under barbiturate anesthesia and 100 per cent oxygen administration, are shown (Figure 6); they are due to a reflex mediated through the vagi (Figure 7). The clinical implications of this effect are discussed.

The increasing effectiveness of small doses of barbiturates, with increase in depth of anesthesia, and the reciprocal relationship of pulmonary ventilation to increasing barbiturate dosage are discussed.

The use of barbiturates appears to be contraindicated in conditions where the blood oxygen may be low or the carbon dioxide high. If these conditions occur during barbiturate anesthesia, the results can be disastrous. Not only is it important to maintain a good blood color under the barbiturates, it is equally important to see to it that the pulmonary ventilation is adequate in order to prevent the piling up of carbon dioxide in the tissues. The use of synthetic carbon dioxide is contraindicated as a respiratory stimulant during barbiturate anesthesia unless artificial respiration is being 
given. In this case probably 5 per cent carbon dioxide should be administered in order to avoid excessive depletion of carbon dioxide.

\section{BIBLIOGRAPHY}

1. Best, C. H., and Taylor, N. B., The Physiological Basis of Medical Practice. Williams and Wilkins, Baltimore, 1939.

2. Cordier, D., and Heymans, C., Le Centre Respiratoire. Hermann, Paris, 1935.

3. Gesell, R., and Moyer, C. A., The variability and incidence of types of breathing in the anesthetized dog. Quart. J. Exper. Physiol., 1935, 24, 315.

4. Gesell, R., and Moyer, C. A., The dual excitatory action of the vagal stretch reflex. Am. J. Physiol., 1941, 131, 674.
5. Henderson, Y., Resuscitation. J. A. M. A., 1924, 83, 758.

6. Marshall, E. K., Jr., and Rosenfeld, M., Depression of respiration by oxygen. J. Pharmacol. and Exper. Therap., 1936, 57, 437.

7. Mosso, A., L'apnée produite par l'oxygéne. Arch. ital. de biol., 1904, 41, 138.

8. Moyer, C. A., and Beecher, H. K., Central stimulation of respiration during anoxia. (In press.)

9. Moyer, C. A., and Beecher, H. K., Effect of evipal upon the integration of respiratory control mechanisms. (In press.)

10. Moyer, C. A., and Beecher, $H$. K., The influence of evipal upon the Hering-Breuer reflex. (In press.)

11. Schmidt, C. F., Macleod's Physiology in Modern Medicine. Mosby, St. Louis, 1941, 9th ed. 